\title{
Post-percutaneous coronary intervention angina: From physiopathological mechanisms to individualized treatment
}

\author{
Leonardo De Luca ${ }^{1}$, Giuseppe M.C. Rosano ${ }^{2}$, Ilaria Spoletini ${ }^{2}$ \\ ${ }^{1}$ Department of Cardiosciences, A.O. San Camillo Forlanini, Rome, Italy \\ ${ }^{2}$ Center for Clinical and Basic Research, Department of Medical Sciences, \\ IRCCS San Raffaele Pisana, Rome, Italy
}

\begin{abstract}
Chronic ischemic heart disease (IHD) is a multifactorial disease with different underlying pathogenetic mechanisms. Percutaneous coronary intervention (PCI) is widely used in patients with IHD in order to reduce angina recurrence. However, after complete or incomplete revascularization procedures, patients may still present anginal symptoms, with a detrimental impact on quality of life and prognosis.

This review summarizes the pathogenic mechanisms and the main challenges encountered in the diagnosis and management of post-PCI angina. (Cardiol J 2022; 29, 5: 850-857)

Key words: angina, ischemic heart disease, percutaneous coronary intervention, medical therapy, quality of life
\end{abstract}

\section{Introduction}

Ischemic heart disease (IHD) is the leading cause of death and disability for both sexes and its prevalence increases in an ageing population $[1,2]$. The most frequent, and often the first manifestation of IHD, is chronic stable angina that affects approximately 112 million people worldwide [3, 4]. Besides pharmacological treatment, percutaneous coronary intervention (PCI) is widely used worldwide in IHD patients in order to reduce angina recurrence. However, up to $30 \%$ of IHD patients with stable angina continue experiencing symptoms despite treatment and revascularization procedures $[5,6]$.

Many post-PCI patients are burdened with recurrence of angina, impaired exercise capacity and quality of life. In fact, angina prevails over myocardial infarction (MI) and heart failure as a reason for impaired quality of life and disability [7]. Greater symptoms of physical limitation are strong- ly predictive of secondary events and poorer survival, independently of other factors [7].

Finally, a common phenomenon is represented by readmissions following PCI. Indeed, approximately $25 \%$ of patients have unplanned readmissions within 6 months [8]. This is due to several factors, $44 \%$ of which are cardiac reasons [8]. Interestingly, angina and coronary artery disease (CAD) are the biggest contributors to the readmissions due to cardiac reasons within 30 days and 1 year after the index PCI [8]. Readmissions after PCI may be considered as an adverse outcome for the patient and an unnecessary cost for the healthcare system.

Taking into account all these issues, the present reviews summarize the physiopathological mechanisms and the main challenges faced by patients with post-PCI angina, with a main focus on relapses of angina symptoms, choice of treatment and its optimization.

Address for correspondence: Leonardo De Luca, MD, PhD, FACC, FESC, Department of Cardiosciences; Division of Cardiology, A.O. San Camillo Forlanini, Circonvallazione Gianicolense, 87, 00152 Roma, Italy, tel: +39-06-58704419, e-mail: leo.deluca@libero.it; ldeluca@scamilloforlanini.rm.it

Received: 19.08.2020 Accepted: 13.02.2021 Early publication date: 9.04.2021

This article is available in open access under Creative Common Attribution-Non-Commercial-No Derivatives 4.0 International (CC BY-NC-ND 4.0) license, allowing to download articles and share them with others as long as they credit the authors and the publisher, but without permission to change them in any way or use them commercially. 


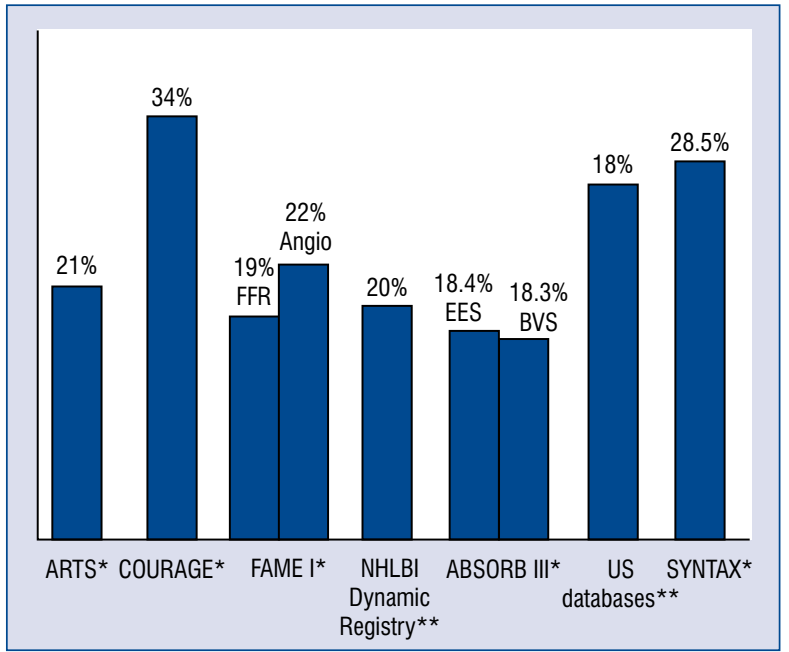

Figure 1. Incidence of recurrent post-percutaneous coronary intervention angina according to main randomized clinical trials $\left({ }^{*}\right)$ and registries $\left({ }^{* *}\right)$; BVS bioresorbable vascular scaffold; EES - everolimus-eluting stent; FFR — fractional flow reserve.

\section{Recurrence of ischemia and angina in post-PCI patients}

Figure 1 shows the incidence of angina recurrence after PCI in recent randomized clinical trials and international registries. In a study including more than 1000 stable angina patients evaluated with an exercise test after successful planned PCI, 29\% still had an abnormal result at 1 month, which reached $31 \%$ of cases at 6 months [9]. Accordingly, meta-analyses of studies and registries in post-PCI patients demonstrated that, within 1 year after successful PCI, the recurrence of angina ranges between $20 \%$ and $30 \%$ [10] and, within 3 years, angina persisted or reoccurred in up to $40 \%$ of cases, leading to higher healthcare costs [11]. Of note, a real-world analysis [11] on the clinical and economic burden associated with post$\mathrm{PCI}$ angina recurrence found that total healthcare costs in the first year after the index PCI were 1.8 times greater for those with angina or chest pain compared to angina-free patients.

Mechanisms underlying post-PCI angina recurrence are multiple and may include non-cardiovascular, cardiovascular non-coronary and coronary causes (Fig. 2). These latter may be functional and structural.

\section{Functional mechanisms}

Nowadays, functional reasons prevail over the structural ones and microvascular dysfunction is found in $64 \%$ of angina patients, in the absence of obstructive functionally significant epicardial

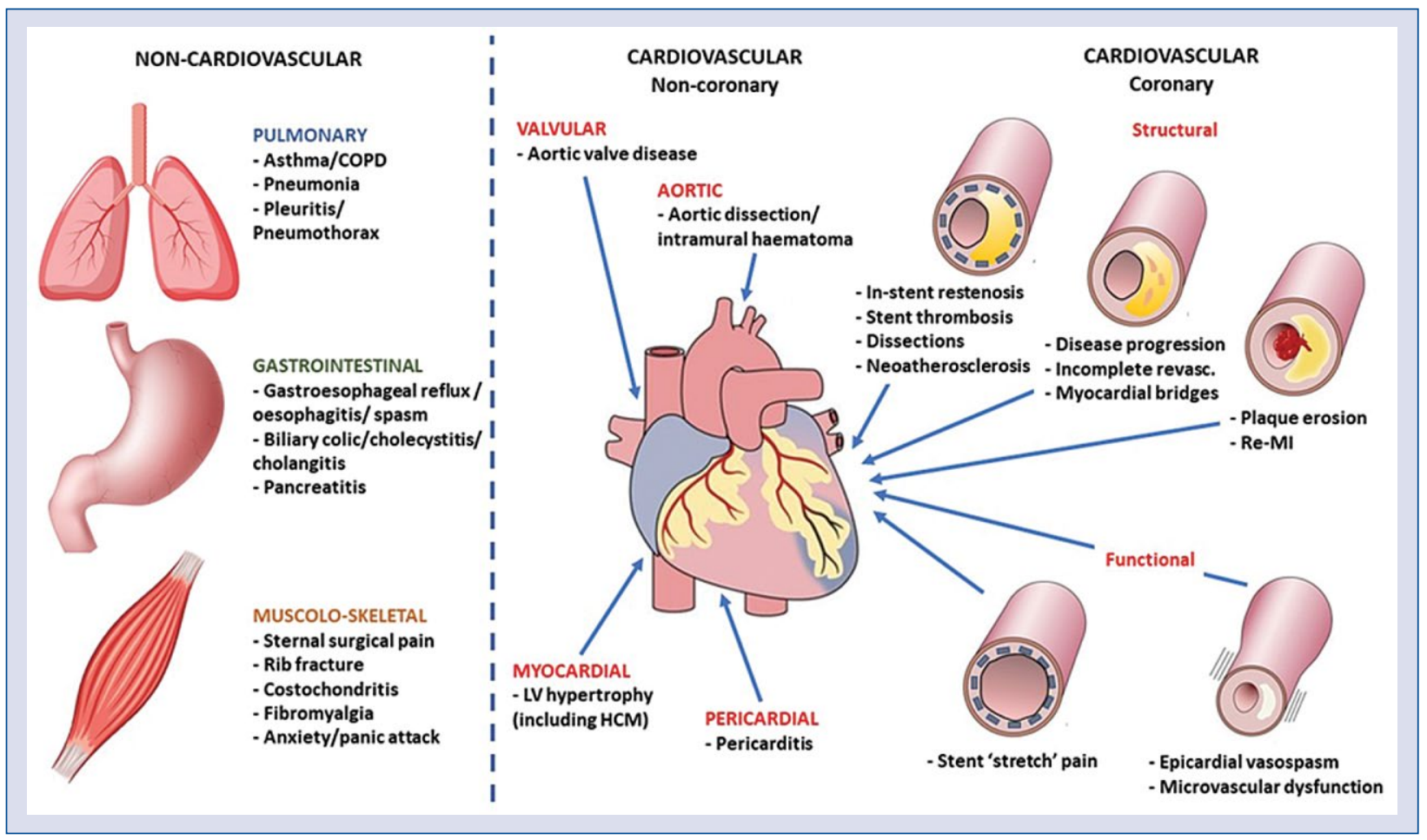

Figure 2. Cardiovascular and non-cardiovascular mechanisms of post-percutaneous coronary intervention angina recurrence; COPD - chronic obstructive pulmonary disease; HCM - hypertrophic cardiomyopathy; LV - left ventricle; $\mathrm{Ml}$ - myocardial infarction. 
stenosis, with a slightly superior prevalence of female sex [12]. Coronary artery vasospasm is also prevalent and is associated with silent myocardial ischemia, effort-induced angina and MI [12]. Similarly, myocardial bridging, a congenital anomaly in which a segment of a coronary artery presents an intramuscular course under a "bridge" of overlying myocardium, may cause vessel compression in systole, resulting in hemodynamic changes that may be associated with myocardial ischemia and angina [11].

Unfortunately, there is a paucity of data on the rate of functional reasons for ischemia along with epicardial stenosis due to an obsolete view that epicardial stenosis was the main reason for ischemia and angina. Last but not least, another key pathophysiological mechanism underlying symptoms and signs of myocardial ischemia, either in the presence or in the absence of an obstructive stenosis, is represented by myocardial cellular metabolic disturbances. The latter may cause ischemia and angina, even after removal of significant stenosis, further highlighting the need of a paradigm shift in stable IHD [13].

For all of these reasons, a functional evaluation is pivotal in PCI patients. There is evidence that a functional evaluation of coronary vasculature during PCI is feasible and improves a post-PCI drug treatment approach, patients' symptoms and quality of life [14]. As demonstrated by the Fractional flow reserve versus Angiography for Multivessel Evaluation (FAME 2) trial [15], routine measurement of fractional flow reserve in patients with multivessel CAD who are undergoing PCI with drug-eluting stents significantly reduced the rate of the composite endpoint of death, nonfatal MI, and repeat revascularization at 1 year. Due to its long-term safety, fractional flow reserve guidance of multivessel PCI should be the standard of care, as also elucidated by the FAME 1 [16].

\section{Structural mechanisms}

Structural causes of post-PCI angina include in-stent restenosis, stent thrombosis, progression of atherosclerotic disease in other coronary segments and incomplete revascularization. The incidence of stent thrombosis and in-stent restenosis, the two major causes of stent failure, has considerably been reduced in recent years by the introduction of new-generation drug-eluting stents [17]. Finally, it was investigated as to whether the type of stent influences frequency of angina after PCI. One study found no significant association between stent type and angina at 1 year after PCI
[18]. Similarly, the A BioreSORBable vascular scaffold versus drug-eluting stent in coronary disease (ABSORB) III trial [19] found no differences in adverse events at 1 year in CAD patients treated with an everolimus-eluting bioresorbable vascular scaffold, as compared with an everolimus-eluting cobalt-chromium stent.

Recurrence of angina due to the progression of coronary atherosclerosis in coronary segments different from those treated with PCI, it is also infrequent in the months after the procedure (only $5 \%$ of major adverse events were related to non-culprit lesions in the Providing Regional Observations to Study Predictors of Events in the Coronary Tree [PROSPECT] study at 1 year follow up [20]), even though it accounts for approximately half of recurrent coronary events. A more common scenario is currently represented by incomplete coronary artery revascularization (IR), with incidence rates ranging from $17 \%$ to $85 \%$ in post-PCI patients $[21,22]$. Such a huge variability is due to differences in study definitions of IR as well in the methodology used to analyse its frequency [23]. Regardless the type of revascularization, IR significantly impacts patient prognosis, increasing the risk of death, MI, repeated revascularization, adverse events and lifestyle-limiting angina [23]. Predictors of IR are older age, presence of multiple comorbidities, complex coronary lesions, hyperlipidemia, total occlusion and number of diseased vessels [23]. As such, IR is considered a marker of complexity that allows the identification of high-risk patients in whom medical therapy is therefore pivotal [24]. Of note, the Ranolazine in patients with Incomplete reVascularisation after Percutaneous Coronary Intervention (RIVER-PCI) study [25] aimed to prove the efficacy of ranolazine in about 2500 patients with IR after PCI. Although this trial confirmed that ischemia-driven events in patients with angina and incomplete revascularization following PCI are common (27\% over 1.8 years), it failed to prove prognostic benefits of the drug in this population [25]. However, there were significant improvements in the frequency of angina following PCI in both arms, with no differences between ranolazine vs. placebo at 1 month (86.6 vs. $85.8, \mathrm{p}=0.62$ ) or 12 months ( 88.4 vs. 88.5 , $\mathrm{p}=0.6$ ). Patients with diabetes appeared to have a benefit with ranolazine for angina frequency at 6 months ( 88.3 vs. 85.4, $\mathrm{p}=0.033$; $\mathrm{p}$ for interaction $=0.02)$. This difference, however, dissipated by 12 months $(\mathrm{p}=0.18)$. Notably, this trial had important limitations since it included a mixed group of patients with IR, including untreated chronic total 
occlusions and diffuse distal disease. In addition, the functional significance of untreated CAD was not routinely assessed.

\section{Heart rate control in post-PCI angina patients}

Another key issue in post-PCI angina patients is poor control of heart rate (HR). It is well-known that resting HR has an important prognostic role [26], since it independently predicts total and cardiovascular mortality in angina patients. Even among patients treated with PCI, HR at discharge is a strong predictor of mortality [27]. As such, HR is a component of both ischemic and bleeding risk scores. This is due to the role of HR in atherogenesis, atherosclerotic plaque formation and progression, and vascular remodeling [28]. Further, HR acts as a trigger of ischemia in patients with CAD [29]. Conversely, HR reduction leads to clinical benefits and, for this reason, lowering HR is a therapeutic target for angina [30].

The latest 2019 European Society of Cardiology guidelines for the management of chronic coronary syndromes (CCS) [2] continue recommending target levels of resting HR between 55 and $60 \mathrm{bpm}$. Unfortunately, the latest registries on CCS suggest poor control of resting HR in this population. For instance, in the prospeCtive observational LongitudinAl RegIstry oF patients with stable coronary arterY disease (CLARIFY) registry [31], including more than 32,000 stable angina patients, $50 \%$ of the symptomatic angina patients had resting HR above $70 \mathrm{bpm}$, in spite of the beta-blocker therapy, which was taken by $75 \%$ of the patients. In the same registry, HR above $70 \mathrm{bpm}$ was associated with higher prevalence and severity of angina.

\section{Choice of anti-anginal drugs/ /individualized treatment}

Due to the multifactorial origin of IHD, in which different pathogenetic mechanisms may co-exist, leading to different clinical pictures with different predominances of symptoms over time [32], it is now been ascertained that patients need several anti-angina drugs in order to control symptoms, following a patient-oriented approach (Fig. 3). The choice of treatment should be related to the mechanisms causing angina, co-morbidities, potential drug-interactions and tolerability. Thus, an individualized approach to angina treatment, the "Diamond" approach, which takes into consideration all these factors, has been proposed (Fig. 4) [32].

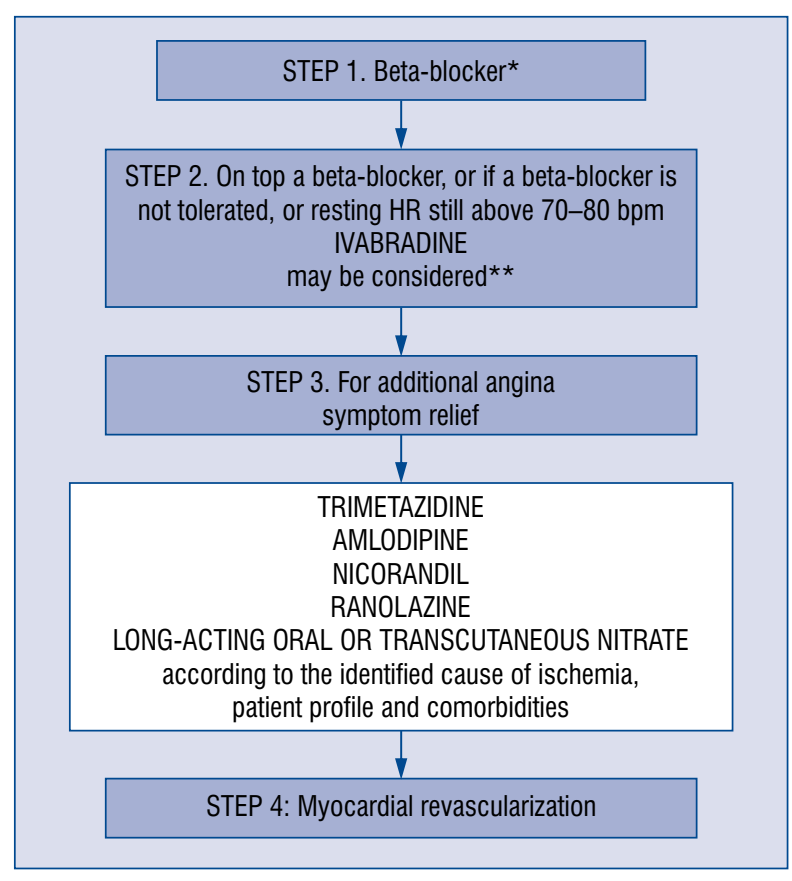

Figure 3. Flowchart of stable angina pectoris treatment; HR - heart rate.

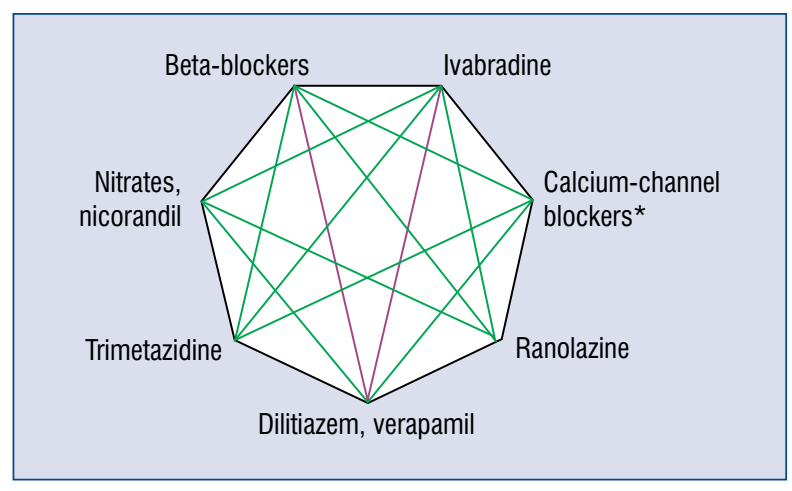

Figure 4. Combinations among classes of antianginal drugs according to the Diamond approach; *dihydropyridines.

In particular, current first line anti-anginals, beta-blockers and calcium-channel blockers have not proven to have prognostic benefits (except for patients within 1 year after MI), as demonstrated by the CLARIFY study [33]. Further, recent meta-analyses found no evidence of superiority of one anti-angina class over another in reducing ischemia and angina [34].

The latest CCS guidelines [2] also acknowledged the lack of evidence of superiority amongst the various anti-angina classes, and despite whether the line categorization is kept, they confirmed 
the need of a patient tailored approach, endorsing the early use of the so called "second line drugs" along with the "first line drugs", in order to provide adequate treatment according to the individual characteristics of the patient.

For all these reasons, more recent drugs with proven additional anti-anginal efficacy should be considered earlier in post-PCI symptomatic patients, along with the so called "first-line" anti-anginal drugs, given that the categorization of an antianginal drug of first or second line is not confirmed [35]. Thus, ivabradine, trimetazidine and ranolazine should be considered, as described elsewhere [32].

Briefly, ivabradine was found to reduce symptoms and improve quality of life in a post-hoc analysis on angina patients with a history of revascularization, who remained symptomatic in spite of an individually optimized dose of a beta-blocker [36]. A recent study [37] in patients with residual ischemia after PCI, demonstrated ivabradine benefits on significant reduction of $\mathrm{HR}$, lower incidence of angina during the stress test and improvements in functional capacity.

As for trimetazidine, it has proven benefits in patients with recurrent angina after PCI in spite of beta-blocker therapy such as preventing recurrence of angina, reducing restenosis, with a good safety profile [38].

Yet, it should be noted that some of these studies are single-center or open-label. The efficAcy and safety of Trimetazidine in patients with angina pectoris having been treated by Percutaneous Coronary Intervention (ATPCI) trial [39], was a randomized, multicenter, placebo controlled trial on more than 6000 post-PCI patients, which failed to demonstrate significant benefits of trimetazidine vs. placebo on the primary efficacy endpoint, a composite of cardiac death, hospital admission for a cardiac event, recurrence or persistence of angina requiring other antianginal drugs or recurrence or persistence of angina requiring a coronary angiography. However, it is important to underline that the ATPCI study was not designed to evaluate antianginal properties of trimetazidine since patients included were asymptomatic and at low risk [39].

\section{Optimization of anti-angina therapy}

Despite its importance, anti-anginal therapy is still often neglected in post-PCI angina patients. In the Clinical Outcomes Utilizing Revascularization and Aggressive Drug Evaluation (COURAGE) trial [40], only $60 \%$ of the patients were on optimized medical therapy after PCI. In the Suivi d'une cohorte de patients COROnariens stables en région NORd-Pas-de-Calais (CORONOR) registry [41], the average number of anti-anginal drugs in post-PCI patients was rather low (mean: 1,4). In the recent International Study of Comparative Health Effectiveness with Medical and Invasive Approaches (ISCHEMIA) trial [42], optimal medical therapy was prescribed, and risk factors control was obtained in more than 5000 patients with moderate to severe ischemia. The results demonstrated no superiority of PCI as an initial strategy on top of optimized medical therapy over optimized medical therapy alone. However, in the overall trial population, which included $35 \%$ of participants without angina at baseline, patients randomly assigned to the invasive strategy had greater improvement in angina-related health status than those assigned to the conservative strategy. The modest mean differences favoring the invasive strategy in the overall group reflected minimal differences among asymptomatic patients and larger differences among patients who had had angina at baseline [43].

It is even more striking that, in a study following post primary PCI patients [44], among the $30 \%$ who reported angina within 6 weeks after the procedure, $68 \%$ remained treated only with beta-blocker, and did not receive a second antianginal drug.

Another main issue observed in clinical practice is the de-escalation of antianginal medications after PCI. There is evidence that down-titration is associated with an increased risk of angina recurrence and worsening of health status, particularly among patients with incomplete revascularization [23]. Interestingly, in the aforementioned RIVER-PCI study [25], $67 \%$ of the patients were taking $0-1$ anti-ischemic/angina drug in spite of the incomplete revascularization in parallel with the $44 \%$ reporting daily or weekly angina after the procedure.

The STable Coronary Artery Diseases RegisTry (START) study [45], a prospective, observational, nationwide study aimed to evaluate the presentation, management, treatment and quality of life of patients with stable $\mathrm{CAD}$, revealed that treatment is still suboptimal in patients with angina. Although angina patients more frequently received antianginal drugs compared to patients without angina, the combinations of angina relief drugs were rarely employed.

Such an inadequate post-PCI anti-angina treatment could be due to different reasons. First, from a socio-psychological point of view, the desire of 
both healthcare professionals and patients to believe that the problem is solved may lead to some kind of inertia. Second, there are reasons linked to the healthcare system, such as the lack of systematic monitoring of symptoms after PCI. A German study [46] demonstrated that $10 \%$ of ambulatory cardiologists did not ask patients about symptoms after PCI and 19\% did not consider initiating drug therapy in angina patients with overruled significant coronary stenosis.

Third, a discrepancy between patient and doctor perceptions of burden of the disease may very often lead to under-recognition of angina. Up to $60 \%$ of the angina cases are not recognized by physicians in ambulatory practice, leading to lower rate of angina treatment up-titration [47].

A recent multinational European physician survey [48], on 659 general practitioners and cardiologists evaluating more than 1900 stable angina patients, found a striking underestimation of the disease burden, especially in elderly, women, and those patients with a long-standing diagnosis (more than 2 years). Moreover, patients who previously had a PCI had more severe stable angina, despite more intense medical treatment, than patients without previous PCI.

All these data demonstrate that close monitoring of stable angina patients and optimization of anti-angina therapy, even after a successful PCI, is mandatory in order to adequately treat symptoms and alleviate the disease burden.

\section{Conclusions}

Recurrence of angina is a frequent and still neglected condition after contemporary PCI. History of symptoms, clinical examination and functional imaging are essential to guide healthcare professionals in the search for possible underlying reasons for angina persistence and relapses in post-PCI patients. Optimizing anti-angina therapy is a necessary step, especially in absence of regional wall motion abnormalities.

Thus, an efficacious and repeated monitoring may help improve post-PCI management in clinical practice and, also, may prevent an excessive and unnecessary use of PCI before optimizing medical therapy.

\section{Funding}

Sponsorship for this review was provided by Servier. Editorial assistance, article processing charges and open access fee were funded by Servier, France.

\section{Conflict of interest: None declared}

\section{References}

1. Sanchis-Gomar F, Perez-Quilis C, Leischik R, et al. Epidemiology of coronary heart disease and acute coronary syndrome. Ann Transl Med. 2016; 4(13): 256, doi: 10.21037/atm.2016.06.33, indexed in Pubmed: 27500157.

2. Knuuti J, Wijns W, Saraste A, et al. ESC Scientific Document Group. 2019 ESC Guidelines for the diagnosis and management of chronic coronary syndromes. Eur Heart J. 2020; 41(3): 407-477, doi: 10.1093/eurheartj/ehz425, indexed in Pubmed: 31504439.

3. Kureshi F, Shafiq A, Arnold SV, et al. The prevalence and management of angina among patients with chronic coronary artery disease across US outpatient cardiology practices: insights from the Angina Prevalence and Provider Evaluation of Angina Relief (APPEAR) study. Clin Cardiol. 2017; 40(1): 6-10, doi: 10.1002/ clc.22628, indexed in Pubmed: 28146269.

4. Moran AE, Forouzanfar MH, Roth GA, et al. The global burden of ischemic heart disease in 1990 and 2010: the Global Burden of Disease 2010 study. Circulation. 2014; 129(14): 1493-1501, doi: 10.1161/CIRCULATIONAHA.113.004046, indexed in Pubmed: 24573351.

5. Peterson E. The burden of angina pectoris and its complications [corrected]. Clin Cardiol. 2007; 30(2 Suppl 1): I10-I15, doi: 10.1002/clc.20047, indexed in Pubmed: 18373325.

6. Roth GA, Johnson CO, Abate KH, et al. The burden of cardiovascular diseases among US states, 1990-2016. JAMA Cardiol. 2018; 3(5): 375-389, doi: 10.1001/jamacardio.2018.0385, indexed in Pubmed: 29641820.

7. Steg PG, Greenlaw N, Tendera M, et al. Prospective Observational Longitudinal Registry of Patients With Stable Coronary Artery Disease (CLARIFY) Investigators. Prevalence of anginal symptoms and myocardial ischemia and their effect on clinical outcomes in outpatients with stable coronary artery disease: data from the International Observational CLARIFY Registry. JAMA Intern Med. 2014; 174(10): 1651-1659, doi: 10.1001/jamainternmed.2014.3773, indexed in Pubmed: 25110899.

8. Kwok CS, Shah B, Al-Suwaidi J, et al. Timing and causes of unplanned readmissions after percutaneous coronary intervention: insights from the nationwide readmission database. JACC Cardiovasc Interv. 2019; 12(8): 734-748, doi: 10.1016/j. jcin.2019.02.007, indexed in Pubmed: 30928446.

9. Huqi A, Morrone D, Guarini G, et al. Stress testing after complete and successful coronary revascularization. Can J Cardiol. 2016; 32(8): 986.e23-986.e29, doi: 10.1016/j.cjca.2015.12.025, indexed in Pubmed: 27038505.

10. Ben-Yehuda O, Kazi DS, Bonafede M, et al. Angina and associated healthcare costs following percutaneous coronary intervention: A real-world analysis from a multi-payer database. Catheter Cardiovasc Interv. 2016; 88(7): 1017-1024, doi: 10.1002/ ccd.26365, indexed in Pubmed: 26774951.

11. Crea F, Bairey Merz CN, Beltrame JF, et al. Mechanisms and diagnostic evaluation of persistent or recurrent angina following percutaneous coronary revascularization. Eur Heart J. 2019; 40(29): 2455-2462, doi: 10.1093/eurheartj/ehy857, indexed in Pubmed: 30608528.

12. Sara JD, Widmer RJ, Matsuzawa Y, et al. Prevalence of coronary microvascular dysfunction among patients with chest pain and nonobstructive coronary artery disease. JACC Cardiovasc Interv. 2015; 8(11): 1445-1453, doi: 10.1016/j.jcin.2015.06.017, indexed in Pubmed: 26404197. 
13. Marzilli M, Merz CN, Boden WE, et al. Obstructive coronary atherosclerosis and ischemic heart disease: an elusive link! J Am Coll Cardiol. 2012; 60(11): 951-956, doi: 10.1016/j. jacc.2012.02.082, indexed in Pubmed: 22954239.

14. Ford TJ, Stanley B, Good R, et al. Stratified medical therapy using invasive coronary function testing in angina: the CorMicA trial. J Am Coll Cardiol. 2018; 72(23 Pt A): 2841-2855, doi: 10.1016/j.jacc.2018.09.006, indexed in Pubmed: 30266608.

15. Fearon WF, Nishi T, De Bruyne B, et al. Clinical outcomes and cost-effectiveness of fractional flow reserve-guided percutaneous coronary intervention in patients with stable coronary artery disease: three-year follow-up of the FAME 2 trial (fractional flow reserve versus angiography for multivessel evaluation). Circulation. 2018; 137(5): 480-487, doi: 10.1161/CIRCULATIONAHA.117.031907, indexed in Pubmed: 29097450.

16. Nunen Lv, Zimmermann F, Tonino P, et al. Fractional flow reserve versus angiography for guidance of $\mathrm{PCI}$ in patients with multivessel coronary artery disease (FAME): 5 -year follow-up of a randomised controlled trial. Lancet. 2015; 386(10006): 1853-1860, doi: 10.1016/s0140-6736(15)00057-4.

17. Stefanini GG, Windecker S. Stent thrombosis: no longer an issue with newer-generation drug-eluting stents? Circ Cardiovasc Interv. 2012; 5(3): 332-335, doi: 10.1161/CIRCINTERVENTIONS.112.970970, indexed in Pubmed: 22715449.

18. Gaglia MA, Torguson R, Lipinski MJ, et al. Frequency of angina pectoris after percutaneous coronary intervention and the effect of metallic stent type. Am J Cardiol. 2016; 117(4): 526-531, doi: 10.1016/j.amjcard.2015.11.036, indexed in Pubmed: 26739394.

19. Ellis SG, Kereiakes DJ, Metzger DC, et al. ABSORB III Investigators. Everolimus-Eluting bioresorbable scaffolds for coronary artery disease. N Engl J Med. 2015; 373(20): 1905-1915, doi: 10.1056/NEJMoa1509038, indexed in Pubmed: 26457558.

20. Stone GW, Maehara A, Lansky AJ, et al. PROSPECT Investigators. A prospective natural-history study of coronary atherosclerosis. N Engl J Med. 2011; 364(3): 226-235, doi: 10.1056/ NEJMoa1002358, indexed in Pubmed: 21247313.

21. Rosner GF, Kirtane AJ, Genereux P, et al. Impact of the presence and extent of incomplete angiographic revascularization after percutaneous coronary intervention in acute coronary syndromes: the Acute Catheterization and Urgent Intervention Triage Strategy (ACUITY) trial. Circulation. 2012; 125(21): 2613-2620, doi: 10.1161/CIRCULATIONAHA.111.069237, indexed in Pubmed: 22550156.

22. Généreux P, Palmerini T, Caixeta A, et al. Quantification and impact of untreated coronary artery disease after percutaneous coronary intervention: the residual SYNTAX (Synergy Between PCI with Taxus and Cardiac Surgery) score. J Am Coll Cardiol. 2012; 59(24): 2165-2174, doi: 10.1016/j.jacc.2012.03.010, indexed in Pubmed: 22483327.

23. Dauerman HL. Reasonable incomplete revascularization. Circulation. 2011; 123(21): 2337-2340, doi: 10.1161/CIRCULATIONAHA.111.033126.

24. Alexander KP, Weisz G, Prather K, et al. Effects of ranolazine on angina and quality of life after percutaneous coronary intervention with incomplete revascularization: results from the ranolazine for incomplete vessel revascularization (RIVER-PCI) trial. Circulation. 2016; 133(1): 39-47, doi: 10.1161/CIRCULATIONAHA.115.019768, indexed in Pubmed: 26555329.

25. Weisz G, Généreux P, Iñiguez A, et al. RIVER-PCI investigators. Ranolazine in patients with incomplete revascularisation after percutaneous coronary intervention (RIVER-PCI): a multicentre, randomised, double-blind, placebo-controlled trial. Lancet. 2016; 387(10014): 136-145, doi: 10.1016/S0140-6736(15)00459-6, indexed in Pubmed: 26474810.

26. Fox K, Ford I, Steg PG, et al. BEAUTIFUL investigators. Heart rate as a prognostic risk factor in patients with coronary artery disease and left-ventricular systolic dysfunction (BEAUTIFUL): a subgroup analysis of a randomised controlled trial. Lancet. 2008; 372(9641): 817-821, doi: 10.1016/S0140-6736(08)61171-X, indexed in Pubmed: 18757091.

27. Antoni ML, Boden H, Delgado V, et al. Relationship between discharge heart rate and mortality in patients after acute myocardial infarction treated with primary percutaneous coronary intervention. Eur Heart J. 2012; 33(1): 96-102, doi: 10.1093/eurheartj/ ehr293, indexed in Pubmed: 21862462.

28. Giannoglou GD, Chatzizisis YS, Zamboulis C, et al. Elevated heart rate and atherosclerosis: an overview of the pathogenetic mechanisms. Int J Cardiol. 2008; 126(3): 302-312, doi: 10.1016/j. ijcard.2007.08.077, indexed in Pubmed: 18068835.

29. Kop WJ, Verdino RJ, Gottdiener JS, et al. Changes in heart rate and heart rate variability before ambulatory ischemic events(1). J Am Coll Cardiol. 2001; 38(3): 742-749, doi: 10.1016/s07351097(01)01451-6, indexed in Pubmed: 11527627.

30. Androulakis E, Tousoulis D, Papageorgiou N, et al. Heart rate as a therapeutic target in angina pectoris. Curr Pharm Des. 2013; 19(9): 1562-1568, indexed in Pubmed: 23016714.

31. Steg P, Ferrari R, Ford I, et al. Heart rate and use of beta-blockers in stable outpatients with coronary artery disease. PLoS One. 2012; 7(5): e36284, doi: 10.1371/journal.pone.0036284.

32. Ferrari R, Camici PG, Crea F, et al. Expert consensus document: A ,diamond' approach to personalized treatment of angina. Nat Rev Cardiol. 2018; 15(2): 120-132, doi: 10.1038/nrcardio.2017.131, indexed in Pubmed: 28880025.

33. Sorbets E, Steg PG, Young R, et al. CLARIFY investigators. Beta-blockers, calcium antagonists, and mortality in stable coronary artery disease: an international cohort study. Eur Heart J. 2019; 40(18): 1399-1407, doi: 10.1093/eurheartj/ehy811, indexed in Pubmed: 30590529.

34. Ferrari R, Pavasini R, Camici PG, et al. Anti-anginal drugs-beliefs and evidence: systematic review covering 50 years of medical treatment. Eur Heart J. 2019; 40(2): 190-194, doi: 10.1093/ eurhearti/ehy504, indexed in Pubmed: 30165445.

35. Pavasini R, Camici PG, Crea F, et al. Anti-anginal drugs: systematic review and clinical implications. Int J Cardiol. 2019; 283: 55-63, doi: 10.1016/j.ijcard.2018.12.008, indexed in Pubmed: 30538056.

36. Zarifis J, Grammatikou V, Kallistratos M, et al. Antianginal efficacy of ivabradine in patients with history of coronary revascularization. Angiology. 2017; 68(1): 10-18, doi: 10.1177/0003319716630499, indexed in Pubmed: 26960667.

37. Calcagno S, Infusino F, Dettori O, et al. Effects of ivabradine on residual myocardial ischemia after PCI evaluated by stress echocardiography. Cardiol Res Pract. 2019; 2019: 9185876, doi: 10.1155/2019/9185876, indexed in Pubmed: 31061733.

38. Chen J, Zhou S, Jin J, et al. Chronic treatment with trimetazidine after discharge reduces the incidence of restenosis in patients who received coronary stent implantation: a 1-year prospective follow-up study. Int J Cardiol. 2014; 174(3): 634-639, doi: 10.1016/j.ijcard.2014.04.168, indexed in Pubmed: 24809921.

39. Ferrari R, Ford I, Fox K, et al. A randomized, double-blind, placebocontrolled trial to assess the efficAcy and safety of Trimetazidine in patients with angina pectoris having been treated by percutaneous 
coronary intervention (ATPCI study): Rationale, design, and baseline characteristics. Am Heart J. 2019; 210: 98-107, doi: 10.1016/j. ahj.2018.12.015, indexed in Pubmed: 30771737.

40. Spertus JA, Maron DJ, Cohen DJ, et al. Clinical Outcomes Utilizing Revascularization and Aggressive Drug Evaluation (COURAGE) Trial Investigators and Coordinators. Frequency, predictors, and consequences of crossing over to revascularization within 12 months of randomization to optimal medical therapy in the Clinical Outcomes Utilizing Revascularization and Aggressive Drug Evaluation (COURAGE) trial. Circ Cardiovasc Qual Outcomes. 2013; 6(4): 409-418, doi: 10.1161/CIRCOUTCOMES.113.000139, indexed in Pubmed: 23838107.

41. Hamon M, Lemesle G, Meurice T, et al. Elective coronary revascularization procedures in patients with stable coronary artery disease: incidence, determinants, and outcome (from the CORONOR study). JACC Cardiovasc Interv. 2018; 11(9): 868-875, doi: 10.1016/j.jcin.2018.02.018, indexed in Pubmed: 29747917.

42. Maron DJ, Hochman JS, Maron DJ, et al. ISCHEMIA Research Group. Initial invasive or conservative strategy for stable coronary disease. N Engl J Med. 2020; 382(15): 1395-1407, doi: 10.1056/NEJMoa1915922, indexed in Pubmed: 32227755.

43. Spertus JA, Jones PG, Maron DJ, et al. ISCHEMIA Research Group. Health-status outcomes with invasive or conservative care in coronary disease. N Engl J Med. 2020; 382(15): 1408-1419, doi: 10.1056/NEJMoa1916370, indexed in Pubmed: 32227753.
44. Fanaroff AC, Kaltenbach LA, Peterson ED, et al. Management of persistent angina after myocardial infarction treated with percutaneous coronary intervention: insights from the TRANSLATE-ACS study. J Am Heart Assoc. 2017; 6(10), doi: 10.1161/ JAHA.117.007007, indexed in Pubmed: 29051217.

45. De Luca L, Temporelli PL, Lucci D, et al. START Investigators. Current management and treatment of patients with stable coronary artery diseases presenting to cardiologists in different clinical contexts: a prospective, observational, nationwide study. Eur J Prev Cardiol. 2018; 25(1): 43-53, doi: 10.1177/2047487317740663, indexed in Pubmed: 29124952.

46. Berliner D, Maier LS, Wollenberg U, et al. Clinical care for patients with recurrent myocardial ischemia in Germany - the VOICES trial. J Thorac Dis. 2018; 10(Suppl 15): S1777-S1784, doi: 10.21037/jtd.2017.10.123, indexed in Pubmed: 30034852.

47. Arnold SV, Grodzinsky A, Gosch KL, et al. Predictors of physician under-recognition of angina in outpatients with stable coronary artery disease. Circ Cardiovasc Qual Outcomes. 2016; 9(5): 554-559, doi: 10.1161/CIRCOUTCOMES.116.002781, indexed in Pubmed: 27531922.

48. Ambrosio G, Collins P, Dechend R, et al. StaBle Angina: PeRceptIon of NeeDs, Quality of Life and ManaGemEnt of Patients (BRIDGE Study) - a Multinational European Physician Survey. Angiology. 2019; 70(5): 397-406, doi: 10.1177/0003319718796313, indexed in Pubmed: 30149731. 